Article

\title{
Analytical and Experimental Study of Recycling Baffled Double-Pass Solar Air Heaters with Attached Fins
}

\author{
Chii Dong Ho *, Hsuan Chang, Rei Chi Wang and Chun Sheng Lin \\ Energy and Opto-Electronic Materials Research Center, Department of Chemical and Materials \\ Engineering, Tamkang University, Tamsui, New Taipei City 25137, Taiwan; \\ E-Mails: nhchang@mail.tku.edu.tw (H.C.); rich.wang@cppcb.com.tw (R.C.W.); \\ cicadas0908@hotmail.com (C.S.L.)
}

* Author to whom correspondence should be addressed; E-Mail: cdho@mail.tku.edu.tw;

Tel.: +886-2-2621-5656 (ext. 2724); Fax: +886-2-2620-9887.

Received: 25 January 2013; in revised form: 14 March 2013 / Accepted: 14 March 2013 /

Published: 28 March 2013

\begin{abstract}
The study of the heat transfer of solar air heaters with a new design using an absorbing plate with fins and baffles, which facilitate the recycling of flowing air, is reported. The mathematical formulation and analytical analysis for such a recyclic baffled double-pass solar air heater were developed theoretically. The performance of the device was studied experimentally as well. The theoretical predicted and experimental results were compared with another design, i.e., a downward-type single-pass solar air heater without recycle and double-pass operations reported in our previous work. Significant improvement in heat-transfer efficiency is achieved with the baffle and fin design due to the recycling heating and the extended heat transfer area. The effects of mass flow rate and recycle ratio on the heat-transfer efficiency enhancement as well as on the power consumption increment are also discussed.
\end{abstract}

Keywords: heat-transfer efficiency; double-pass; solar air heater; fins attached; baffles

\section{Nomenclature:}

$A_{c}=$ surface area of the collector $=L W\left(\mathrm{~m}^{2}\right)$

$A_{b}=$ total surface area of attached baffles $\left(\mathrm{m}^{2}\right)$

$A_{E}=$ surface area of the edge of collector $=2 L H\left(\mathrm{~m}^{2}\right)$

$A_{f}=$ total surface area of attached fins $\left(\mathrm{m}^{2}\right)$ 
$A_{t}=$ the area of absorbing plate less the welded area of fins $\left(\mathrm{m}^{2}\right)$

$A_{t f}=$ cross section area of fins $\left(\mathrm{m}^{2}\right)$

$B_{i}=$ coefficients defined in Equations (A16-A21)

$C_{i}=$ coefficients defined in Equations (A26,A27)

$C_{p}=$ specific heat of air at constant pressure $(\mathrm{J} / \mathrm{kg} \mathrm{K})$

$D_{e, 0}=$ equivalent diameter of downward-type single-pass device defined in Equation (36) (m)

$D_{e, a}=$ equivalent diameter of lower subchannel of double-pass device defined in Equation (36) (m)

$D_{e, b}=$ equivalent diameter of upper subchannel of double-pass device defined in Equation (36) (m)

$F_{i}=$ coefficients defined in Equations (A28-A30)

$f_{F}=$ Fanning friction factor

$G_{i}=$ coefficients defined in Equations (A5-A8) and (A13-A15)

$H=$ height of both upper and lower channels (m)

$H_{f}=$ height of fin (m)

$H_{B}=$ height of baffles (m)

$H_{f}=$ height of fins (m)

$h_{a}=$ heat-transfer coefficient of air in the lower subchannel $\left(\mathrm{W} / \mathrm{m}^{2} \mathrm{~K}\right)$

$h_{b}=$ heat-transfer coefficient of air in the upper subchannel $\left(\mathrm{W} / \mathrm{m}^{2} \mathrm{~K}\right)$

$h_{r}=$ radiative heat-transfer coefficient between two parallel plates $\left(\mathrm{W} / \mathrm{m}^{2} \mathrm{~K}\right)$

$h_{c_{1}-c_{2}}=$ heat transfer coefficient for free convection of air between two glass covers, defined in Equation $(44)\left(\mathrm{W} / \mathrm{m}^{2} \mathrm{~K}\right)$

$h_{r, c_{1}-c_{2}}=$ radiation heat transfer coefficient between two covers, defined in Equation $(45)\left(\mathrm{W} / \mathrm{m}^{2} \mathrm{~K}\right)$

$h_{r, c_{2}-s}=$ radiation heat transfer coefficient from cover 2 to the ambient, defined in

Equation (46)(W/m² $\mathrm{K})$

$h_{r, p-c_{1}}=$ radiation heat transfer coefficient between cover 1 and absorbing plate, defined in

Equation (43) $\left(\mathrm{W} / \mathrm{m}^{2} \mathrm{~K}\right)$

$h_{r, p-R}=$ radiation heat transfer coefficient between absorbing plate andbottom plate, defined in

Equation (44) $\left(\mathrm{W} / \mathrm{m}^{2} \mathrm{~K}\right)$

$h_{w}=$ convective heat-transfer coefficient for air flowing over the outside surface of glass cover $\left(\mathrm{W} / \mathrm{m}^{2} \mathrm{~K}\right)$

$I_{i}=$ coefficients defined in Equations (A31,A32)

$I_{0}=$ incident solar radiation $\left(\mathrm{W} / \mathrm{m}^{2}\right)$

$I_{D}=$ percentage of collector efficiency improvement, defined in Equation (47)

$I_{P}=$ the power consumption increment, defined in Equation (53)

$k=$ thermal conductivity of air $(\mathrm{W} / \mathrm{m} \mathrm{K})$

$k_{B}=$ thermal conductivity of bottom plate $(\mathrm{W} / \mathrm{m} \mathrm{K})$

$k_{f}=$ thermal conductivity of fins $(\mathrm{W} / \mathrm{m} \mathrm{K})$

$k_{s}=$ thermal conductivity of insulator $(\mathrm{W} / \mathrm{m} \mathrm{K})$

$L=$ channel length $(\mathrm{m})$

$l=$ distance between baffles $(\mathrm{m})$ 
$l_{B}=$ thickness of bottom plate $(\mathrm{m})$

$l_{s}=$ thickness of insulator $(\mathrm{m})$

$\ell_{w f, a}=$ lower subchannel friction loss of double-pass solar air heater $(\mathrm{J} / \mathrm{kg})$

$\ell_{w f, b}=$ upper subchannel friction loss of double-pass solar air heater $(\mathrm{J} / \mathrm{kg})$

$\ell_{w f, s}=$ friction loss of downward-type single-pass solar air heater $(\mathrm{J} / \mathrm{kg})$

$\dot{m}=$ total air mass flow rate $(\mathrm{kg} / \mathrm{h})$

$m_{f}=$ coefficient defined in Equation (3)

$M_{a}=$ coefficient defined in Equation (A23) $\left(\mathrm{W} / \mathrm{m}^{2} \mathrm{~K}\right)$

$M_{b}=$ coefficient defined in Equation (A22) $\left(\mathrm{W} / \mathrm{m}^{2} \mathrm{~K}\right)$

$N=$ number of glass cover

$N_{\text {exp }}=$ the number of experimental measurements

$N_{u}=$ Nusselt number

$P_{B}=$ power consumption of baffled solar air heaters (W)

$P_{D}=$ power consumption of baffled double-pass solar air heaters (W)

$P_{S}=$ power consumption of downward-type solar air heaters (W)

$Q_{u}=$ useful energy gain carried away by air (W)

$Q_{\text {loss }}=$ total heat loss rate from the air collector to the surrounding area(W)

$q^{\prime}=$ total heat flow rate of solar air collector with fins attached (W)

$q^{\prime \prime}=$ total heat flow rate of solar air collector with baffles attached (W)

$R=$ recycle ratio

$\mathrm{Re}_{0}=$ Reynolds number in downward-type single-pass solar air heater

$\mathrm{Re}_{a}=$ Reynolds number in lower subchannel of double-pass solar air heater

$\mathrm{Re}_{b}=$ Reynolds number in upper subchannel of double-pass solar air heater

$T_{\text {in }}=$ inlet air temperature $(\mathrm{K})$

$T_{a}(z)=$ axial fluid temperature distribution in lower subchannel $(\mathrm{K})$

$T_{b}(z)=$ axial fluid temperature distribution in upper subchannel $(\mathrm{K})$

$T_{c}=$ temperature of glass cover $(\mathrm{K})$

$T_{a, m}=$ mean fluid temperature in lower subchannel (K)

$T_{b, m}=$ mean fluid temperature in upper subchannel $(\mathrm{K})$

$T_{c, m}=$ mean temperature of glass cover $(\mathrm{K})$

$T_{p}=$ temperature of absorbing plate $(\mathrm{K})$

$T_{p, m}=$ mean temperature of absorbing plate $(\mathrm{K})$

$T_{R}=$ temperature of bottom plate $(\mathrm{K})$

$T_{R, m}=$ mean temperature of bottom plate $(\mathrm{K})$

$T_{s}=$ ambient temperature $(\mathrm{K})$

$t_{f}=$ thickness of fins (m)

$U_{B}=$ loss coefficient from the bottom plate of solar air heater to the ambient environment $\left(\mathrm{W} / \mathrm{m}^{2} \mathrm{~K}\right)$ 
$U_{B-s}=$ loss coefficient from the surfaces of edges and the bottom plate of the solar collector to the ambient environment $\left(\mathrm{W} / \mathrm{m}^{2} \mathrm{~K}\right)$

$U_{c_{1}-s}=$ loss coefficient from glass cover 1 to the ambient environment $\left(\mathrm{W} / \mathrm{m}^{2} \mathrm{~K}\right)$

$U_{E}=$ loss coefficient from the edge of solar air heater to the ambient environment $\left(\mathrm{W} / \mathrm{m}^{2} \mathrm{~K}\right)$

$U_{L}=$ overall loss coefficient $\left(\mathrm{W} / \mathrm{m}^{2} \mathrm{~K}\right)$

$U_{T}=$ loss coefficient from the top of solar air heater to the ambient environment $\left(\mathrm{W} / \mathrm{m}^{2} \mathrm{~K}\right)$

$W=$ width of both upper and lower subchannels (m)

$W_{B}=$ baffle width $(\mathrm{m})$

$\overline{v_{0}}=$ mean air velocity in the downward-type single-pass solar air heater $(\mathrm{m} / \mathrm{s})$

$\overline{v_{a}}=$ mean air velocity in lower subchannel of double-pass solar air heater $(\mathrm{m} / \mathrm{s})$

$\overline{v_{b}}=$ mean air velocity in upper subchannel of double-pass solar air heater $(\mathrm{m} / \mathrm{s})$

$V=$ wind velocity $(\mathrm{m} / \mathrm{s})$

$Y_{i}=$ coefficients defined in Equations $(\mathrm{A} 24, \mathrm{~A} 25)$

$z=$ axial coordinate $(\mathrm{m})$

\section{Greek Letters}

$\alpha_{p}=$ absorptivity of absorbing plate

$\eta_{b}=$ baffle efficiencies of upper and lower channels

$\eta_{D}=$ collector efficiency of downward-type single-pass solar air heater

$\eta_{\exp , i}=$ experimental data of collector efficiency

$\eta_{f}=$ fin efficiency, defined in Equation (2)

$\eta_{\text {theo }, i}=$ theoretical prediction of collector efficiency

$\tau_{g}=$ transmittance of glass cover

$\varepsilon_{g}=$ emissivity of glass cover

$\varepsilon_{R}=$ emissivity of bottom plate

$\varepsilon_{p}=$ emissivity of absorbing plate

$\rho=$ air density $\left(\mathrm{kg} / \mathrm{m}^{3}\right)$

$\mu=$ air viscosity $(\mathrm{kg} / \mathrm{s} \mathrm{m})$

$\xi=$ dimensionless channel length, defined in Equation (15)

$\sigma=$ Stefan-Boltzmann constant $=5.67 \times 10^{-8}\left(\mathrm{~W} / \mathrm{m}^{2} \mathrm{~K}^{4}\right)$

\section{Introduction}

The flat-plate solar air heater [1-5] is considered to be a simple device consisting of one or more glass (or transparent) covers situated above an absorbing plate with the air flowing over [4,5], under [1-3] or simultaneously over and under [6] the absorbing plate. The conventional flat-plate solar air heater has been investigated for heat-transfer efficiency improvement by introducing free convection [7] forced convection [8,9] extended heat-transfer area [10,11] and increased air turbulence [12,13]. 
Moreover, the adoption of the recycle-effect concept can effectively enhance the heat transfer rate and has been applied in many separation processes and reactor designs, as confirmed by the previous works [14-17].Extending from our previous work [18] this study focuses on a new design featuring recycling as well as turbulence and heat transfer area enhancement, as shown in Figure 1.

Figure 1. Double-pass solar air heater with internal baffles and fins.

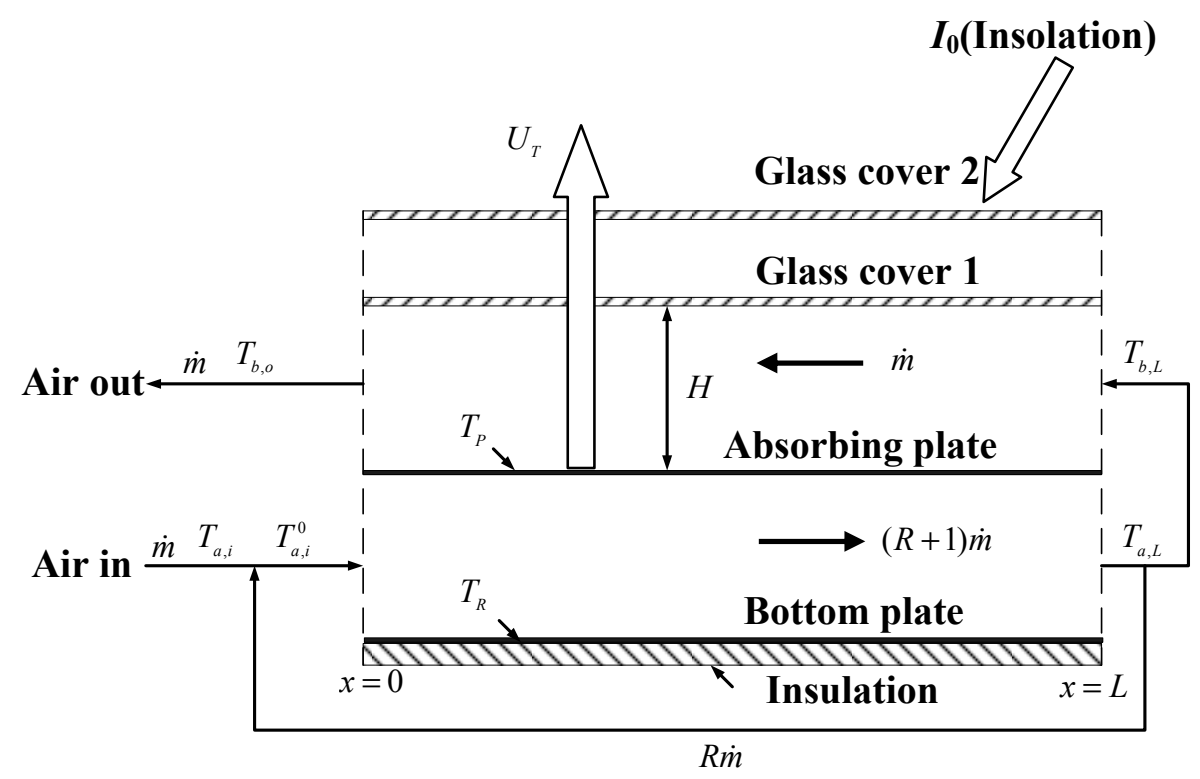

This work presents the theoretical mathematical formulations and the experimental verification for the new solar air heater design. The effects of the recycle ratio and air mass flow rate on the heat transfer rate, heat-transfer efficiency improvement, and the power consumption increment are also delineated.

\section{Mathematical Formulation}

The device proposed is conceptually depicted in Figure 1. An absorbing plate inserted into the air flow channel creates the upper and lower subchannels, which facilitates the double-pass air flow. On both sides of the absorbing plate, baffles and fins guide the air flow and provide turbulence and extra heat transfer area. Like in conventional solar air heaters, two layers of glass with a gap in between are used on top of the upper subchannel to reduce the heat loss to the environment and other sides of the device are thermally insulated.

Figure 2 shows the configuration of the device with recycle. The absorbing plate is inserted in parallel into a parallel-plate channel with width of $\mathrm{W}$ and length of $\mathrm{L}$, and the open conduit is divided into two parts both with height of $\mathrm{H}$. Before entering the lower subchannel, the inlet air with mass flow rate and inlet temperature is premixed with part of the air leaving the lower subchannel with mass flow rate and outlet temperature. The steady-state one-dimensional mathematical model was developed with the assumptions of: (1) the temperature of the absorbing plate, bottom plate and bulk fluids are functions of the flow direction only; (2) both glass covers and flowing air do not absorb radiant energy; (3) except the glass cover, all outside surfaces of the solar air collector are well insulated thermally. 
Figure 2. Configuration of a double-pass solar air heater with recycle.

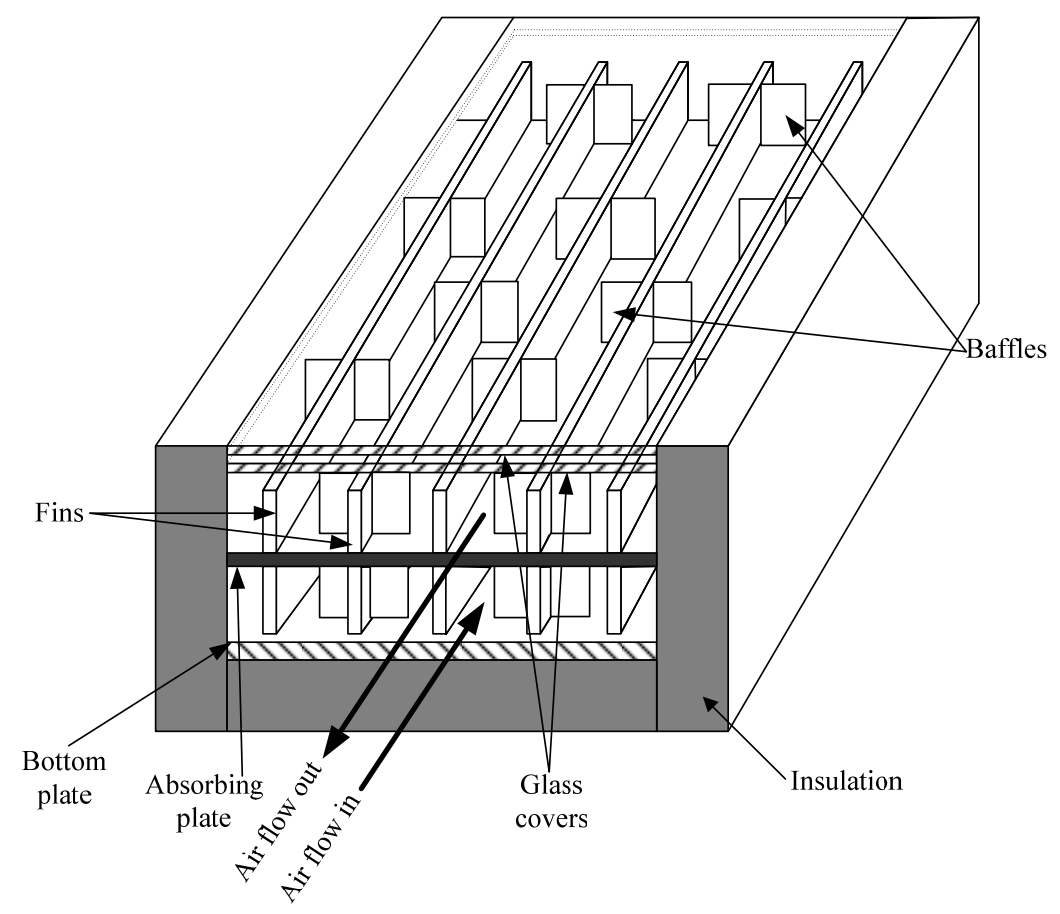

\subsection{Effect of Attaching Fins with Baffles}

The total heat transfer from the absorbing plate with attached fins and baffles to a passing airflow can be written as the following via modifications from Bannett and Myers [19]:

$$
q^{\prime \prime}=h_{i}\left(A_{t}+A_{f} \eta_{f}+A_{b} \eta_{b}\right)\left(T_{p}-T_{i}(z)\right), i=a, b
$$

where the fin efficiency is defined as:

$$
\eta_{f}=\frac{\tanh m_{f} h_{f}}{m_{f} h_{f}}
$$

in which:

$$
m_{f}=\sqrt{\frac{2 h_{i}\left(L+t_{f}\right)}{k_{f} A_{t f}}}
$$

The baffle efficiency $\eta_{b}$ is affected by the density of the baffles, i.e., $W / D_{\mathrm{e}}$ and $l / L$. Following empirical correlations $[20,21]$ the baffle efficiency can be obtained for the fins attached to the lower and upper subchannels as:

$$
\eta_{b}=26.361\left(\frac{W_{B}}{D_{e}}\right)^{-0.454}\left(\frac{l}{L}\right)^{0.634} \text { for lower subchannel }
$$

and:

$$
\eta_{b}=15.583\left(\frac{W_{B}}{D_{e}}\right)^{0.0518}\left(\frac{l}{L}\right)^{0.227} \quad \text { for upper subchannel }
$$




\subsection{Temperature Distributions for the Flowing Air in the Flow Direction}

For the steady-state one-dimensional mathematical model, the energy balances for the flowing air streams, glass cover 1, absorbing plate and bottom plate, are given in Equations (6-10).

For the airflow in upper subchannel:

$$
\frac{-\dot{m} R C_{p}}{W} \frac{d T_{b}(z)}{d z}=h_{b} \phi_{b}\left(T_{p}-T_{b}(z)\right)-h_{b}\left(T_{b}(z)-T_{c_{1}}\right)
$$

For the airflow in lower subchannel:

$$
\left[\frac{(R+1) \dot{m} C_{p}}{W}\right] \frac{d T_{a}(z)}{d z}=h_{a} \phi_{a}\left(T_{p}-T_{a}(z)\right)-h_{a}\left(T_{a}(z)-T_{R}\right)
$$

For the glass cover 1 (inner cover):

$$
h_{r, p-c_{1}}\left(T_{p}-T_{c_{1}}\right)+h_{b}\left(T_{b}(z)-T_{c_{1}}\right)=U_{c_{1}-s}\left(T_{c_{1}}-T_{s}\right)
$$

For the absorbing plate:

$$
I_{0} \alpha_{p} \tau_{g}^{2}=U_{T}\left(T_{p}-T_{s}\right)-U_{B}\left(T_{p}-T_{s}\right)-h_{b} \phi_{b}\left(T_{p}-T_{b}(z)\right)-h_{a} \phi_{a}\left(T_{p}-T_{a}(z)\right)
$$

For the bottom plate

$$
h_{a}\left(T_{a}(z)-T_{R}\right)+h_{r, p-R}\left(T_{p}-T_{R}\right)=U_{B-s}\left(T_{R}-T_{s}\right)
$$

The heat transfer coefficients between airflow and the conduit walls were assumed to be equal, in which:

$$
\begin{gathered}
\phi_{a}=1+\frac{A_{f, a}}{A_{t}} \eta_{f, a}+\frac{A_{b, a}}{A_{t}} \eta_{b, a} \\
\phi_{b}=1+\frac{A_{f, b}}{A_{t}} \eta_{f, b}+\frac{A_{b, b}}{A_{t}} \eta_{b, b}
\end{gathered}
$$

Rearranging Equations (8-10) and solving for $\left(T_{p}-T_{b}(z)\right), \quad\left(T_{b}(z)-T_{c 1}\right), \quad\left(T_{p}-T_{a}(z)\right)$ and $\left(T_{a}(z)-T_{R}\right)$, and then, substituting the results into Equations $(6,7)$, we have the temperature distributions with the dimensionless coordinate in the flow direction as follows:

$$
\begin{gathered}
\frac{d\left(T_{b}(\xi)-T_{s}\right)}{d \xi}=B_{1}\left(T_{b}(\xi)-T_{s}\right)+B_{2}\left(T_{a}(\xi)-T_{s}\right)+B_{3} \\
\frac{d\left(T_{a}(\xi)-T_{s}\right)}{d \xi}=B_{4}\left(T_{b}(\xi)-T_{s}\right)+B_{5}\left(T_{a}(\xi)-T_{s}\right)+B_{6} \\
\xi=z / L .
\end{gathered}
$$

The boundary conditions for solving Equations $(13,14)$ are:

$$
\begin{gathered}
\xi=0, T_{a, i}^{0}=\frac{T_{a, i}+R T_{a, L}}{(1+R)} \\
\xi=1, T_{a}(1)=T_{a, L}, \quad T_{b}(1)=T_{b, L}
\end{gathered}
$$


By following the similar mathematical treatment performed in our previous work [18], the analytical solutions to this device were obtained after transforming Equations $(13,14)$ into $\left(D-B_{1}\right)\left(T_{b}-T_{s}\right)-B_{2}\left(T_{a}-T_{s}\right)=B_{3}$ and $-B_{4}\left(T_{b}-T_{s}\right)+\left(D-B_{5}\right)\left(T_{a}-T_{s}\right)=B_{6}$ with the use of the differential operator notation, in which $D=d / d \xi$.Operate on the second of these with $\left(1 / B_{4}\right)\left(D-B_{1}\right)$ and add to the first equation to obtain Equation (18) with using boundary conditions in Equations (16),(17), and hence, Equation (19) was thus obtained. The temperature distributions of the flowing air for both lower and upper subchannels are thus obtained, respectively:

$$
\begin{gathered}
T_{b}(\xi)=\frac{Y_{1}-B_{5}}{B_{4}} C_{1} e^{Y_{1} \xi}+\frac{Y_{2}-B_{5}}{B_{4}} C_{2} e^{Y_{2} \xi}-\frac{B_{5}\left(B_{3} B_{4}-B_{1} B_{6}\right)}{B_{4}\left(B_{1} B_{5}-B_{2} B_{4}\right)}-\frac{B_{6}}{B_{4}}+T_{s} \\
T_{a}(\xi)=C_{1} e^{Y_{1} \xi}+C_{2} e^{Y_{2} \xi}+\frac{B_{3} B_{4}-B_{1} B_{6}}{B_{1} B_{5}-B_{2} B_{4}}+T_{s}
\end{gathered}
$$

All the coefficients $B_{i}, G_{i}, M_{i}, Y_{i}, C_{i}, F_{i}$ and $I_{i}$ are referred to the Appendix. Once the inlet and outlet temperatures are known, the useful gain may be estimated from the relation:

$$
Q_{u}=\dot{m}(1+R) C_{p}\left(T_{a, L}-T_{a, i}^{0}\right)+\dot{m} C_{p}\left(T_{b, o}-T_{b, L}\right)
$$

or:

$$
Q_{u}=\dot{m}(1+R) C_{p}\left(T_{a, L}-T_{a, i}\right)+\dot{m} C_{p}\left(T_{b, o}-T_{b, L}\right)=\dot{m}\left(T_{b, o}-T_{a, i}\right)
$$

Finally, the collector efficiency $\eta_{D}$ of a baffled double-pass solar air heater with external recycle and attached internal fins, relates the actual useful energy gain to the incident solar radiation, was defined as follows Ho et al.[18]:

$$
\begin{aligned}
\eta_{D}= & \frac{Q_{u}(\text { Useful gain of energy carried away by air })}{I_{0} A_{c}(\text { Total solar radiation incident })} \\
= & \frac{\dot{m} C_{p}\left(T_{b, o}-T_{a, i}\right)}{I_{0} A_{c}}=\tau_{g}^{2} \alpha_{p}-U_{L}\left(T_{p, m}-T_{s}\right) / I_{0}
\end{aligned}
$$

and the airflow outlet temperature is readily obtained from Equation (22), i.e.:

$$
T_{b, o}=T_{a, i}+\left(\eta_{D} I_{0} A_{c} / \dot{m} C_{p}\right)
$$

Equating Equations (22,23), we have:

$$
T_{p, m}=T_{s}+\left(I_{0} \tau_{g}^{2} \alpha_{p} / U_{L}\right)-\frac{\dot{m} C_{p}\left(T_{b, o}-T_{a, i}\right)}{A_{c} U_{L}}
$$

Substitution of Equation (24) into Equation (25) to eliminate $T_{b, o}$ results in:

$$
T_{p, m}=T_{s}+\left(I_{0} / U_{L}\right)\left(\tau_{g}^{2} \alpha_{p}-\eta_{D}\right)
$$

Equation (26) is the expression of $T_{p, m}$ in terms of $\eta_{D}$. 


\subsection{Heat Transfer Coefficients}

The total heat loss rate from the solar air heater to the surrounding is the summation of the top, edge and bottom loss rates, i.e.:

$$
Q_{\text {loss }}=U_{L} A_{c}\left(T_{p, m}-T_{s}\right)=U_{T} A_{c}\left(T_{p, m}-T_{s}\right)+U_{B} A_{c}\left(T_{R, m}-T_{s}\right)+U_{E} A_{E}\left(T_{a, m}+T_{b, m}-2 T_{s}\right)
$$

where the average temperatures $T_{a, m}, T_{b, m}, T_{p, m}$ and $T_{R, m}$ can be obtained by integration and rearrangement of Equations $(10,18,19,26)$, and $U_{T}, U_{B}$ and $U_{E}$ are estimated by Equations $(28,32)$. An empirical equation for $U_{T}$ was developed [22] following the basic procedure in [23] as:

$$
U_{T}=\left\{\frac{N}{\frac{C_{a i r}}{T_{p, m}}\left[\frac{\left(T_{p, m}-T_{s}\right)}{N+f}\right]^{e}}+\frac{1}{h_{w}}\right\}^{-1}+\frac{\sigma\left(T_{p, m}+T_{s}\right)\left(T_{p, m}^{2}+T_{s}^{2}\right)}{\left\{\left(\varepsilon_{p}+0.00591 N h_{w}\right)^{-1}+\frac{\left[2 N+f-1+0.133 \varepsilon_{p}\right]}{\varepsilon_{g}}-N\right\}}
$$

where:

$$
\begin{gathered}
f=\left(1+0.089 h_{w}-0.1166 h_{w} \varepsilon_{p}\right)(1+0.07866 N) \\
C_{\text {air }}=520\left(1-0.00005 \beta^{2}\right) \text { for } 0^{\circ}<\beta<70^{\circ} ; \text { for } \beta>70^{\circ} \text { use } \beta=70^{\circ} \\
e=0.43\left(1-100 / T_{p, m}\right)
\end{gathered}
$$

The edge and bottom loss coefficients depend mainly on the insulation thickness:

$$
U_{B}=U_{E}=k_{s} / l_{s}
$$

Moreover, all heat transfer coefficients in Equations $(6,7)$ are estimated by the following empirical and correction equations. The forced convective heat-transfer coefficient for air flowing in the ducts between two flat plates may be estimated by Kay’s data [24,25]:

$$
N_{u, i}=h_{i} D_{e, i} / k=0.0158 \mathrm{Re}_{i}^{0.8}, i=a, b
$$

The modification of McAdams [25] for turbulent flow in a short conduit:

$$
N_{u, i}=h_{i} D_{e, i} / k=0.0158 \operatorname{Re}_{i}^{0.8}\left[1+\left(D_{e, i} / L\right)^{0.7}\right], \quad i=a, b
$$

The correlation equation for laminar flow was expressed by Heaton et al. [26]:

$$
N_{u, i}=4.4+\frac{0.00398\left(0.7 \operatorname{Re}_{j} D_{e, i} / L\right)^{1.66}}{1+0.0114\left(0.7 \operatorname{Re}_{i} D_{e, i} / L\right)^{1.12}}, i=a, b
$$

in which the characteristic length is the equivalent diameter of the air duct:

$$
D_{e, 0}=\frac{4(2 H W)}{2(2 H+W)}, \quad D_{e, a}=D_{e, b}=\frac{4\left(H W-5 H_{f} t_{f}\right)}{2(H+W)+10 H_{f}}
$$

for downward-type single-pass and double-pass devices, respectively. The average velocities of the downward-type single-pass device and the lower and upper subchannels of the double-pass device are: 


$$
\overline{v_{0}}=\frac{m}{2 H W \rho}, \overline{v_{a}}=\frac{m(1+R)}{\left(H W-5 h_{f} t_{f}\right) \rho}, \overline{v_{b}}=\frac{m}{\left(H W-5 h_{f} t_{f}\right) \rho}
$$

Thus; from Equations (36,37); one obtains the Reynolds numbers of downward-type single-pass and double-pass devices; respectively; for the rectangular ducts:

$$
\operatorname{Re}_{0}=\frac{\rho \overline{v_{0}} D_{e, 0}}{\mu}, \operatorname{Re}_{a}=\frac{\rho \overline{v_{a}} D_{e, a}}{\mu}, \operatorname{Re}_{b}=\frac{\rho \overline{v_{b}} D_{e, b}}{\mu}
$$

The heat transfer coefficients and radiation coefficients in Equations (8-10) were calculated by the following empirical equations. The thermal resistance from glass cover 1 through glass cover 2 to the ambient air, may be expressed as:

$$
\frac{1}{U_{c_{1}-s}}=\frac{1}{U_{T}}-\frac{1}{h_{r, p-c_{1}}+h_{1}}
$$

or:

$$
\frac{1}{U_{c_{1}-s}}=\frac{1}{h_{w}+h_{r, c_{2}-s}}+\frac{1}{h_{c_{1}-c_{2}}+h_{r, c_{1}-c_{2}}}
$$

where the heat-transfer coefficient for free convection of air between two glass covers may be estimated using Hottel's empirical Equation [23] as:

$$
h_{c_{1}-c_{2}}=1.25\left(T_{c_{1, m}}-T_{c_{2, m}}\right)^{0.25}
$$

and the convective heat-transfer coefficient for air flowing over the outside surface of glass cover 2, can be calculated using the following empirical equation given by McAdams [25]:

$$
h_{w}=2.8+3.0 \mathrm{~V}
$$

The radiation coefficients between the two air-duct surfaces may be estimated by assuming a mean radiant temperature equal to the mean fluid temperature, viz.:

$$
\begin{aligned}
& h_{r, p-c 1} \approx 4 \sigma T_{b, m}^{3} /\left[\left(1 / \varepsilon_{p}\right)+\left(1 / \varepsilon_{c_{1}}\right)-1\right] \\
& h_{r, p-R} \approx 4 \sigma T_{a, m}^{3} /\left[\left(1 / \varepsilon_{P}\right)+\left(1 / \varepsilon_{R}\right)-1\right]
\end{aligned}
$$

while those between two glass covers and from glass cover 2 to the ambient are, respectively:

$$
\begin{aligned}
& h_{r, c_{1}-c_{2}}=\frac{\sigma\left(T_{c_{1, m}}^{2}+T_{c_{2, m}}^{2}\right)\left(T_{c_{1, m}}+T_{c_{2, m}}\right)}{\left(1 / \varepsilon_{g}\right)+\left(1 / \varepsilon_{g}\right)-1} \\
& h_{r, c_{2}-s}=\varepsilon_{g} \sigma\left(T_{c_{2, m}}^{2}+T_{s}^{2}\right)\left(T_{c_{2}, m}+T_{s}\right)
\end{aligned}
$$

\subsection{Theoretical Calculation Method for Collector Efficiency}

The calculation procedures for theoretical predictions of collector efficiency and collector efficiency improvement were described as follows. Firstly, with the given collector geometries $\left(A_{c}=0.09 \mathrm{~m}^{2}, H=0.05 \mathrm{~m}, h_{B}=h_{f}=0.05 \mathrm{~m}, L=0.3 \mathrm{~m}, W=0.3 \mathrm{~m}, l=0.12 \mathrm{~m}, l_{B}=l_{s}=0.06 \mathrm{~m}, t_{f}=0.002 \mathrm{~m}\right.$, $\left.W_{B}=0.03 \mathrm{~m}\right)$ and the system properties $\left[\alpha_{p}=0.96, \varepsilon_{g}=0.94, \varepsilon_{p}=0.8, \varepsilon_{R}=0.94, \tau_{g}=0.875\right.$, 
$\left.k_{B}=k_{f}=14.9 \mathrm{~W} /(\mathrm{m} \mathrm{K}), k_{s}=0.033 \mathrm{~W} /(\mathrm{m} \mathrm{K})\right]$, as well as the operating conditions $[\dot{m}=38.52,57.96$ and $77.04 \mathrm{~kg} / \mathrm{hr}, T_{\text {in }}=(30 \pm 0.1){ }^{\circ} \mathrm{C}, T_{s}=(30 \pm 0.1){ }^{\circ} \mathrm{C}, I_{0}=(830 \pm 40)$, and $\left.(1100 \pm 40) \mathrm{W} / \mathrm{m}^{2}, V=1.0 \mathrm{~m} / \mathrm{s}\right]$, the initial guesses for the average temperatures $T_{p, m}, T_{R, m}, T_{c 1, m}, T_{c 2, m}$ are estimated to obtain the heat transfer coefficients and to calculate the temperature distributions of both upper and lower subchannels from Equations (13-17). Secondly, the values of $T_{p, m}, T_{R, m}, T_{c 1, m}, T_{c 2, m}$ are then checked by using Equations (10-12,26), respectively, and new iteration values of $T_{p, m}, T_{R, m}, T_{c 1, m}, T_{c 2, m}$ may be obtained. If the new calculated values of $T_{p, m}, T_{R, m}, T_{c 1, m}, T_{c 2, m}$ are different from the previous iteration values, re-calculated with the proper equations by iteration procedures until the error tolerance is small enough (say less than $10^{-3}$ ), and thus the collector efficiencies $\eta_{D}$ can be calculated by using Equation (23). The application of recycle-effect concept to a solar air heater actually increases the convective heat-transfer coefficient by producing a preheating effect with the hot outgoing air. Results show that this advantage influence can partially or completely offset the decrement of teat transfer driving force (temperature gradient).The collector efficiency improvement $I_{D}$ with comparing the collector efficiency between downward-type single-pass device and the present design of solar air heaters is:

$$
I_{D}=\frac{\eta_{D}-\eta_{S}}{\eta_{S}} \times 100 \%
$$

in which $\eta_{D}$ and $\eta_{S}$, respectively, denote the collector efficiency in baffled double-pass type with fins attached and downward-type single-pass solar air heaters.

\section{Apparatus and Experimental Methods}

A baffled double-pass solar air heater with external recycle (stainless steel of $7 \times 10^{-5} \mathrm{~m}$ thickness) and with five fins attached on both above and under the absorbing plate for experimental studies, are shown in Figures 1 and 2. The collector $(0.3 \mathrm{~m}$ long, $0.3 \mathrm{~m}$ wide, $0.05 \mathrm{~m}$ in height of each subchannel) consists of two glass covers $\left(2.75 \times 10^{-3} \mathrm{~m}\right.$ thickness and $0.05 \mathrm{~m}$ space $)$, a black absorbing plate, baffles welded to the fins, 42 electrical energy supplies $(110 \mathrm{~V}, 125 \mathrm{~W})$ in the part B in Figure 3 and thermal insulation using Styrofoam (0.06 m thickness), as shown in Figure 3 for artificial simulation. The incident solar radiation $I_{0}$ (arrived irradiation)were measured and recorded with an Epply Laboratory Inc. pyranometer and an Instantaneous Solar Radiation meter Model No. 455 also from Epply Laboratory Inc. Before air entered the lower subchannel, a pre-heater was used to ensure a specified temperature [i.e., $T_{\text {in }}=(30 \pm 0.1){ }^{\circ} \mathrm{C}$ ] at the inlet to mix the recycle airflow from the lower subchannel regulated by an adjustable valve. There are two air boxes $(0.3 \mathrm{~m} \times 0.3 \mathrm{~m} \times 0.05 \mathrm{~m})$ with 14 holes $(0.015 \mathrm{~m}$ diameter) were used for air distribution at inlets of both upper and lower subchannels, respectively. Except for the outer glass cover, all parts of the solar air heater were well insulated thermally to minimize the energy loss. 
Figure 3. Schematic diagram of a double-pass solar air heater with artificial simulation.

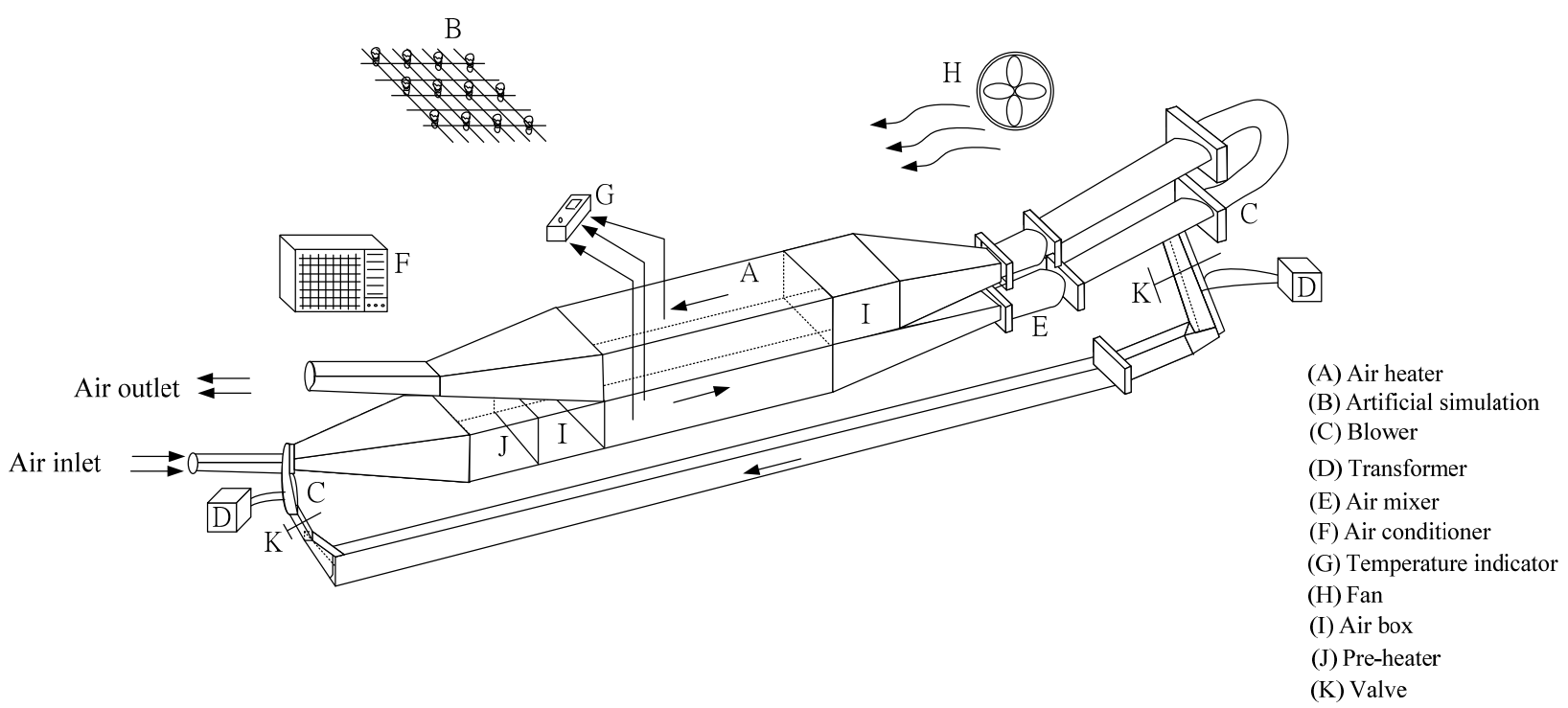

Airflow was steadily supplied by a blower (Model BL model 552, Redmond Co., Owosso, MI, USA) and the mass flow rate controlled by a transformer was measured with Model 24-611 anemomaster from Kanomax Japan Inc. (Osaka, Japan). The air temperatures of absorbing plate and at the inlet and outlet of the solar collector were measured with thermocouples. The ambient temperature $\left[T_{s}=(30 \pm 0.1)^{\circ} \mathrm{C}\right]$ measured at a position $0.15 \mathrm{~m}$ above the outer glass cover with a thermocouple was monitored by using an air conditioner with a fan to provide wind flow of $1.0 \mathrm{~m} / \mathrm{s}$ (as indicated by a Chicago Cenco anemometer, TSI Inc., St. Paul, MN, USA) in the experimental apparatus.

\section{Results and Discussion}

The essential physical properties employed in this study are presented in Table 1, and the operating conditions are $T_{a, I}=303 \mathrm{~K}$, and $\dot{m}=38.52,57.96$ and $77.04 \mathrm{~kg} / \mathrm{h}$. By substituting the specified values into the appropriate equations, theoretical predictions for collector efficiency and airflow outlet temperature with incident solar radiation, mass flow rate and recycle ratio as parameters were obtained. The theoretical predictions and experimental results are plotted in Figures 4-9.

Table 1. Physical properties of air at 1atm [8].

\begin{tabular}{ccccc}
\hline $\boldsymbol{T}(\mathbf{K})$ & $\boldsymbol{\rho}\left(\mathbf{k g} / \mathbf{m}^{\mathbf{3}}\right)$ & $\boldsymbol{C}_{\mathbf{p}}[\mathbf{J} /(\mathbf{k g ~ K})]$ & $\boldsymbol{k}[\mathbf{W} /(\mathbf{m ~ K})]$ & $\boldsymbol{\mu} \mathbf{~ k g} /(\mathbf{m ~ s})]$ \\
\hline 273 & 1.292 & 1006 & 0.0242 & $1.72 \times 10^{-5}$ \\
293 & 1.204 & 1006 & 0.0257 & $1.81 \times 10^{-5}$ \\
313 & 1.127 & 1007 & 0.0272 & $1.90 \times 10^{-5}$ \\
333 & 1.059 & 1008 & 0.0287 & $1.99 \times 10^{-5}$ \\
353 & 0.999 & 1010 & 0.0302 & $2.09 \times 10^{-5}$ \\
\hline
\end{tabular}


Figure 4. Effect of recycle ratio on collector efficiency in a double-pass flat-plate solar air heater with recycle; $I_{0}=830 \mathrm{~W} / \mathrm{m}^{2}, \dot{m}=38.52 \mathrm{~kg} / \mathrm{h}$.

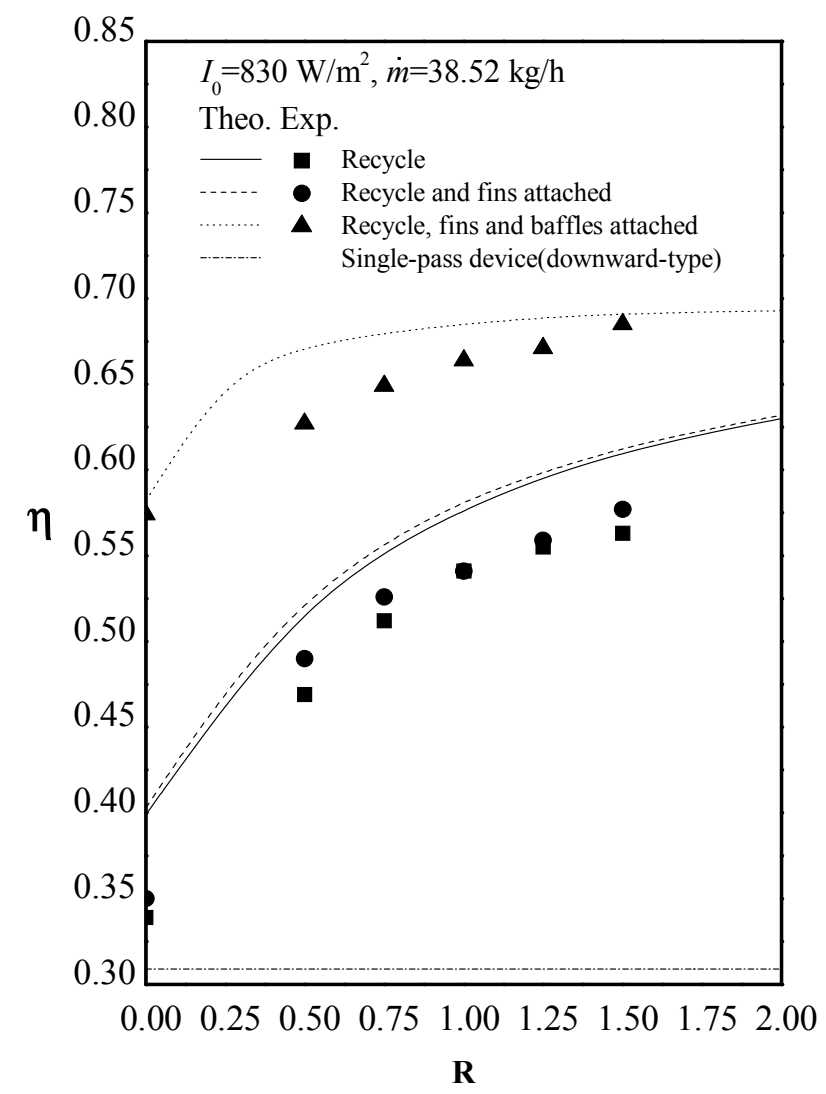

Figure 5. Effect of recycle ratio on collector efficiency in a double-pass flat-plate solar air heater with recycle; $I_{0}=830 \mathrm{~W} / \mathrm{m}^{2}, \dot{m}=57.96 \mathrm{~kg} / \mathrm{h}$.

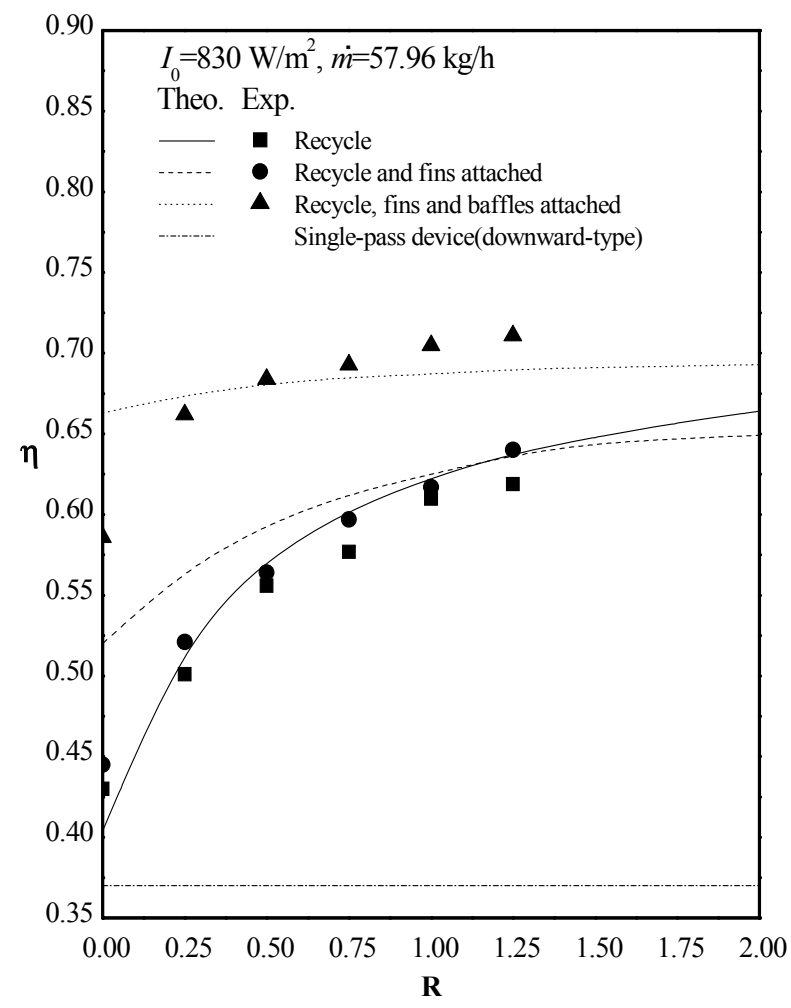


Figure 6. Effect of recycle ratio on collector efficiency in a double-pass flat-plate solar air heater with recycle; $I_{0}=830 \mathrm{~W} / \mathrm{m}^{2}, \dot{m}=77.04 \mathrm{~kg} / \mathrm{h}$.

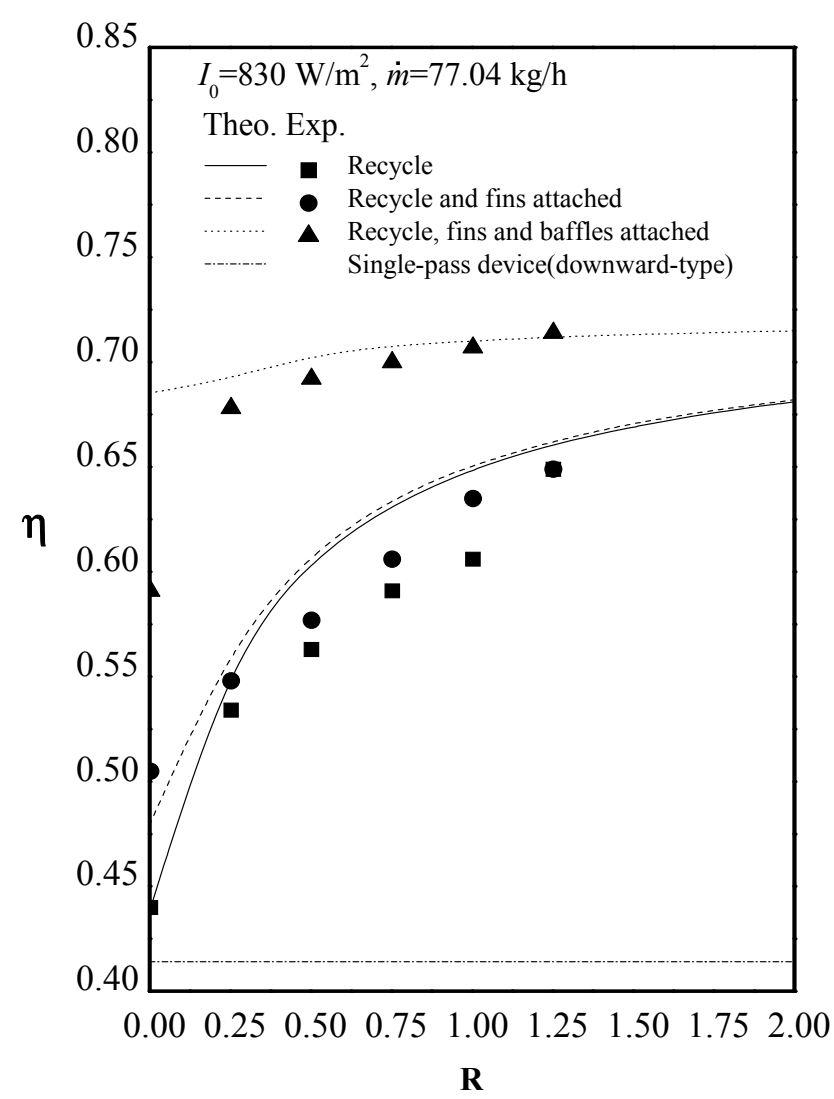

Figure 7. Effect of recycle ratio on collector efficiency in a double-pass flat-plate solar air heater with recycle; $I_{0}=1100 \mathrm{~W} / \mathrm{m}^{2}, \dot{m}=38.52 \mathrm{~kg} / \mathrm{h}$.

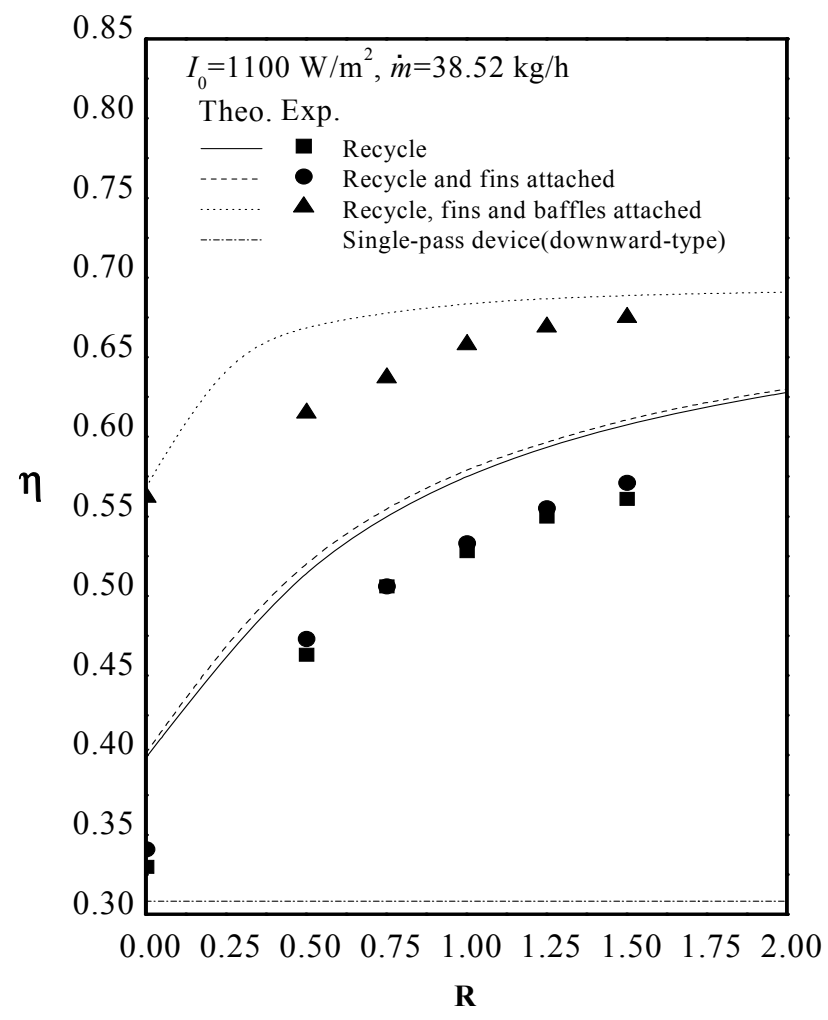


Figure 8. Effect of recycle ratio on collector efficiency in a double-pass flat-plate solar air heater with recycle; $I_{0}=1100 \mathrm{~W} / \mathrm{m}^{2}, \dot{m}=57.96 \mathrm{~kg} / \mathrm{h}$.

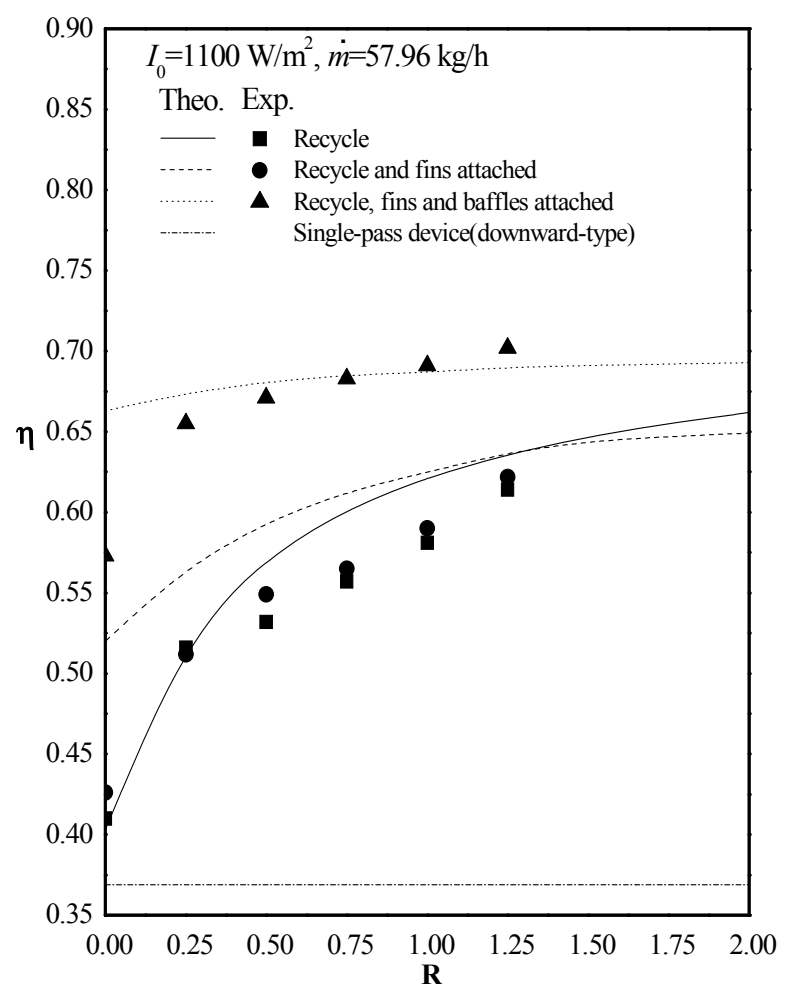

Figure 9. Effect of recycle ratio on collector efficiency in a double-pass flat-plate solar air heater with recycle; $I_{0}=1100 \mathrm{~W} / \mathrm{m}^{2}, \dot{m}=77.04 \mathrm{~kg} / \mathrm{h}$.

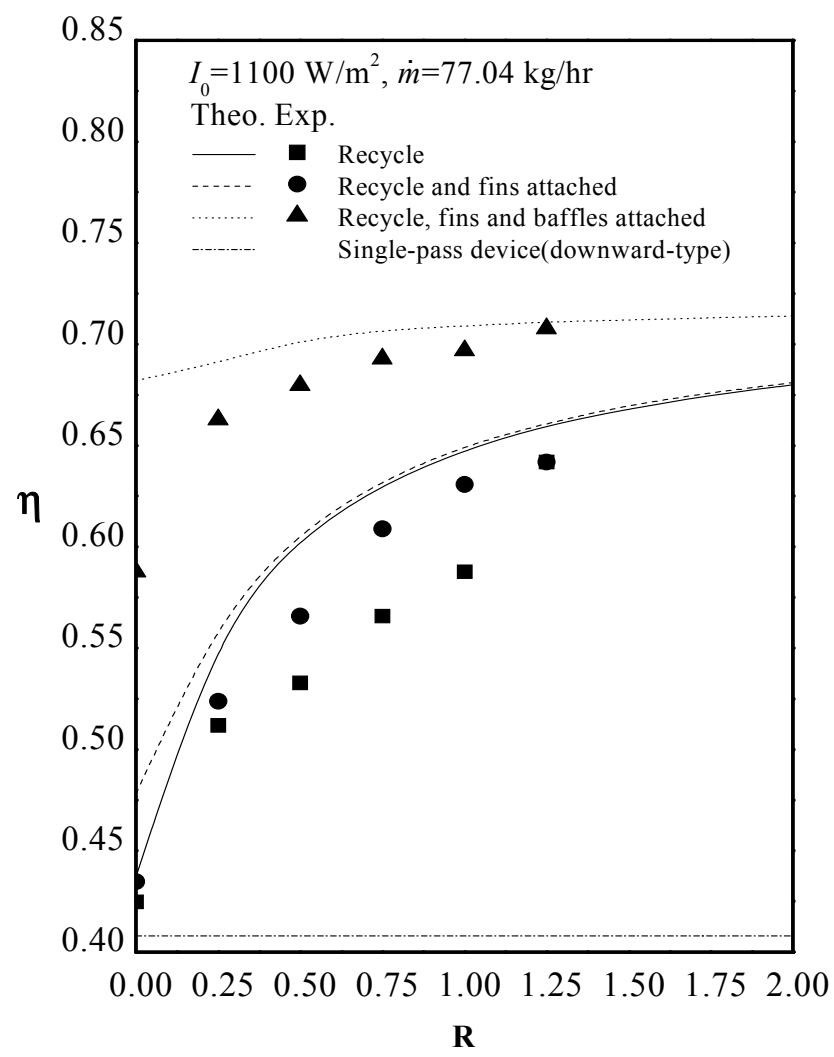


This experimental study for recyclic baffled solar air heaters with attaching internal fins was conducted under artificial simulation, as shown in Figure 3. The agreement between the experimental results and theoretical predictions is fairly good, and the operation with recycle-effect device substantially improves the collector efficiency, as confirmed by Figures 4-9. In order to validate the accuracy of the experimental results as compared to theoretical predictions, the following definition of error analysis was made:

$$
E=\frac{1}{N_{\exp }} \sum_{i=1}^{N_{\text {exp }}} \frac{\left|\eta_{\text {theo }, i}-\eta_{\text {exp }, i}\right|}{\eta_{\text {theo }, i}}
$$

where $N_{\text {exp }}, \eta_{\text {theo, } i}$ and $\eta_{\text {exp, } i}$ indicate the experimental measurements, theoretical predictions and experimental data of collector efficiencies, respectively. The error analysis may be calculated with the results in Figures 4-9 by using Equation (48). The error analysis of the experimental measurements is of $3.19 \times 10^{-2} \leqq E \leqq 9.86 \times 10^{-2}$ and presented in Table 2 .

The theoretical predictions of $I_{D}$ for the system of the present interest were also calculated by Equation (47), and the results are also listed in Tables 3 and 4. It is shown that the considerable improvement in collector efficiency is obtained if the operation is carried out with fins and baffles attached under external recycle.

Table 2. The accuracy analysis of the experimental results.

\begin{tabular}{ccccc}
\hline $\boldsymbol{I}_{\mathbf{0}}\left(\mathbf{W} / \mathbf{m}^{\mathbf{2}}\right)$ & $\dot{m} \mathbf{( k g} / \mathbf{h})$ & Recycle & Recycle + Fins & Recycle + Fins + Baffles \\
\hline \multirow{3}{*}{830} & 38.52 & $8.79 \times 10^{-2}$ & $6.80 \times 10^{-2}$ & $3.20 \times 10^{-2}$ \\
\cline { 2 - 5 } & 57.96 & $3.83 \times 10^{-2}$ & $5.24 \times 10^{-2}$ & $3.44 \times 10^{-2}$ \\
\cline { 2 - 5 } & 77.04 & $4.41 \times 10^{-2}$ & $3.40 \times 10^{-2}$ & $3.19 \times 10^{-2}$ \\
\hline \multirow{3}{*}{1100} & 38.52 & $9.86 \times 10^{-2}$ & $8.53 \times 10^{-2}$ & $3.96 \times 10^{-2}$ \\
\cline { 2 - 5 } & 57.96 & $4.57 \times 10^{-2}$ & $8.50 \times 10^{-2}$ & $3.41 \times 10^{-2}$ \\
\cline { 2 - 5 } & 77.04 & $4.41 \times 10^{-2}$ & $5.10 \times 10^{-2}$ & $4.18 \times 10^{-2}$ \\
\hline
\end{tabular}

Table 3. Theoretical predictions of heat-transfer efficiency improvement $I_{D}$ for $I_{0}=830 \mathrm{~W} / \mathrm{m}^{2}$.

\begin{tabular}{cccccccccc}
\hline \multirow{2}{*}{$\mathbf{R}$} & \multicolumn{3}{c}{ Recycle } & \multicolumn{3}{c}{ Recycle + Fins } & \multicolumn{3}{c}{ Recycle + Fins + Baffles } \\
\cline { 2 - 10 } & \multicolumn{3}{c}{$\mathbf{m} \mathbf{( k g / h )}$} \\
\hline- & 38.52 & 57.96 & 77.04 & 38.52 & 57.96 & 77.04 & 38.52 & 57.96 & 77.04 \\
0.00 & 29.13 & 9.19 & 5.80 & 30.42 & 40.54 & 15.70 & 88.35 & 79.19 & 65.46 \\
0.25 & 50.16 & 41.35 & 35.27 & 52.75 & 52.97 & 36.47 & 111.97 & 82.16 & 67.15 \\
0.50 & 67.64 & 54.86 & 46.38 & 69.58 & 60.54 & 47.10 & 117.48 & 84.05 & 69.81 \\
0.75 & 78.96 & 62.97 & 52.66 & 80.58 & 65.68 & 53.38 & 120.06 & 85.14 & 71.01 \\
1.00 & 86.73 & 68.38 & 56.76 & 88.35 & 68.92 & 57.25 & 121.68 & 85.68 & 71.50 \\
1.25 & 92.88 & 72.43 & 59.66 & 93.85 & 72.16 & 59.90 & 122.98 & 86.49 & 71.98 \\
1.50 & 97.41 & 75.14 & 61.59 & 98.38 & 74.05 & 62.08 & 123.62 & 86.76 & 72.22 \\
1.75 & 100.97 & 77.57 & 63.29 & 101.62 & 74.86 & 63.53 & 123.95 & 87.03 & 72.46 \\
\hline
\end{tabular}


Table 4. Theoretical predictions of heat-transfer efficiency improvement $I_{D}$ for $I_{0}=1100 \mathrm{~W} / \mathrm{m}^{2}$.

\begin{tabular}{cccccccccc}
\hline \multirow{2}{*}{$\mathbf{R}$} & \multicolumn{3}{c}{ Recycle } & \multicolumn{4}{c}{ Recycle + Fins } & \multicolumn{3}{c}{ Recycle + Fins + Baffles } \\
\cline { 2 - 10 } & \multicolumn{3}{c}{$\mathbf{m}(\mathbf{k g} / \mathbf{h})$} \\
\hline- & 38.52 & 57.96 & 77.04 & 38.52 & 57.96 & 77.04 & 38.52 & 57.96 & 77.04 \\
0.00 & 29.22 & 9.21 & 7.11 & 30.19 & 40.65 & 17.16 & 84.42 & 79.40 & 67.16 \\
0.25 & 50.32 & 41.46 & 37.25 & 52.92 & 53.12 & 38.48 & 111.69 & 82.38 & 69.36 \\
0.50 & 67.86 & 55.01 & 48.28 & 69.81 & 60.70 & 49.02 & 117.53 & 84.28 & 72.06 \\
0.75 & 78.90 & 63.14 & 54.66 & 80.52 & 65.85 & 55.15 & 120.13 & 85.37 & 73.28 \\
1.00 & 87.01 & 68.56 & 58.82 & 88.31 & 69.11 & 59.31 & 122.08 & 85.91 & 73.77 \\
1.25 & 92.86 & 72.36 & 61.76 & 93.83 & 72.36 & 62.01 & 123.05 & 86.72 & 74.26 \\
1.50 & 97.40 & 75.34 & 63.73 & 98.38 & 74.25 & 64.22 & 123.70 & 86.99 & 74.51 \\
1.75 & 100.97 & 77.51 & 65.44 & 101.95 & 75.07 & 65.69 & 124.03 & 87.26 & 74.75 \\
2.00 & 103.90 & 79.40 & 66.67 & 104.55 & 75.61 & 66.91 & 124.35 & 87.53 & 75.00 \\
\hline
\end{tabular}

The collector efficiency improvement increases with increasing incident solar radiation and recycle ratio as well as mass flow rate owing to turbulence increment and forced convective heat-transfer coefficient enhancement, as shown in Tables 3 and 4, especially for operating at larger air flow rate $\dot{m}$. The improvement in collector efficiency by recycle operation is obtained more than $64 \%$ as compared to downward-type single-pass device. In addition, the larger incident solar radiation is associated with the higher absorbing plate temperature of the solar air collector, resulting in the increment of the heat transfer efficiency. For instances, the heat-transfer efficiency improvements with fins and baffles for $\dot{m}=77.04 \mathrm{~kg} / \mathrm{h}$ and $R=2$, are $72.71 \%$ and $75.0 \%$ for $I_{0}=830$ and $1100 \mathrm{~W} / \mathrm{m}^{2}$, respectively. Accordingly, the order of heat transfer efficiencies of flat plate collectors are: collector with fins and baffles $>$ collector with fins $>$ collector without fins and baffles, as indicated in Tables 3 and 4.

The power consumptions of the solar air heater with fins attached are calculated by the correlation equation. The power consumptions for downward-type single-pass and double-pass solar air heaters without attached baffles, respectively, are as follows:

$$
\begin{gathered}
P_{S}=m \ell_{w f, s}=m \frac{2 f_{F}{\overline{v_{0}}}^{2} L}{D_{e}} \\
P_{D}=m \ell_{w f, a}+m(1+R) \ell_{w f, b}=m \frac{2 f_{F}{\overline{v_{a}}}^{2} L}{D_{e, a}}+m(1+R) \frac{2 f_{F}{\overline{v_{b}}}^{2} L}{D_{e, b}}
\end{gathered}
$$

in which:

$$
\begin{gathered}
f_{F}=\frac{24}{\operatorname{Re}}, \text { for laminar flow } \\
f_{F}=0.0790 \operatorname{Re}^{-0.25}, \text { for turbulent flow, } \operatorname{Re}<10^{5}
\end{gathered}
$$

The power consumption increment, $I_{P}$, may be defined as:

$$
I_{P}=\frac{P_{D}-P_{S}}{P_{S}}
$$


The hydraulic dissipated energy in a single-pass device without recycle are $P_{S}=7.68 \times 10^{-6}$, $2.36 \times 10^{-5}$ and $5.23 \times 10^{-5} \mathrm{~W}$, respectively, for $\dot{m}=38.52,57.96$ and $77.04 \mathrm{~kg} / \mathrm{h}$ for mass flow rate. The suitable selections of the operating parameters $(R$ and $\dot{m})$ on considering of both the heat-transfer efficiency improvement, $I_{D}$, and the power consumption increment, $I_{P}$, are presented in Figure 10.

Figure 10. $I_{D} / I_{P} v s$. recycle ratio $R$ with mass flow rate as a parameter.

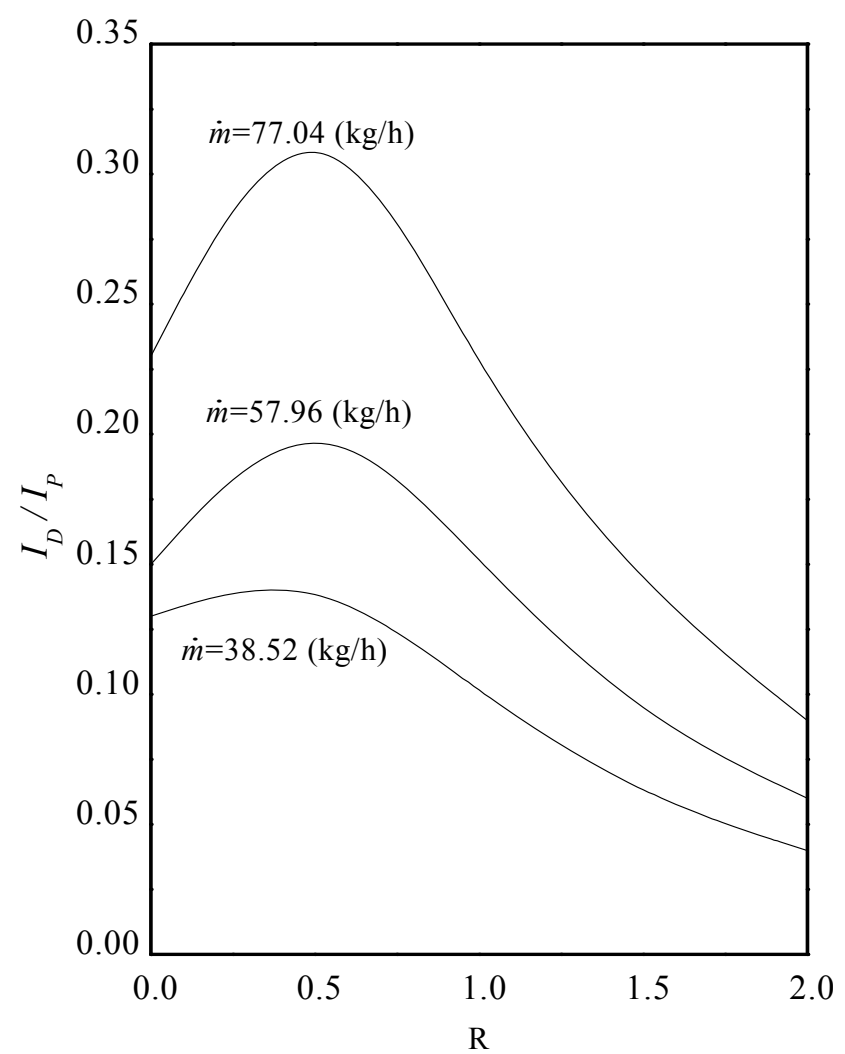

The economically optimal design must take into account the costs of energy and devices. However, for simplicity, only the power consumption is considered in this study. The index of $I_{D} / I_{P}$ is adopted for comparing different designs. Operating double-pass solar air heaters with recycle at $R_{\text {optimal }} \approx 0.5$ gives the maximum value of $I_{D} / I_{P}$, as seen from Figure 10, while the values of $I_{D} / I_{P}$ decrease as the recycle ratio moves away from 0.5 . A remark must be stated that even if only energy criterion is to be considered, because thermal energy and electric power are different in terms of the quality of energy, employing exergy analysis can provide different results from those shown in Figure 10.

The present work is actually the extension previous work [18] except the configuration of recycle. Figure 11 illustrates the graphical representation for comparisons with some experimental results and theoretical predictions obtained in [18] under the same design and operating parameters. With those comparisons, the advantage this study is evident for all mass flow rates and recycle ratios. 
Figure 11. Comparisons of collector efficiency among the present and previous works [18].

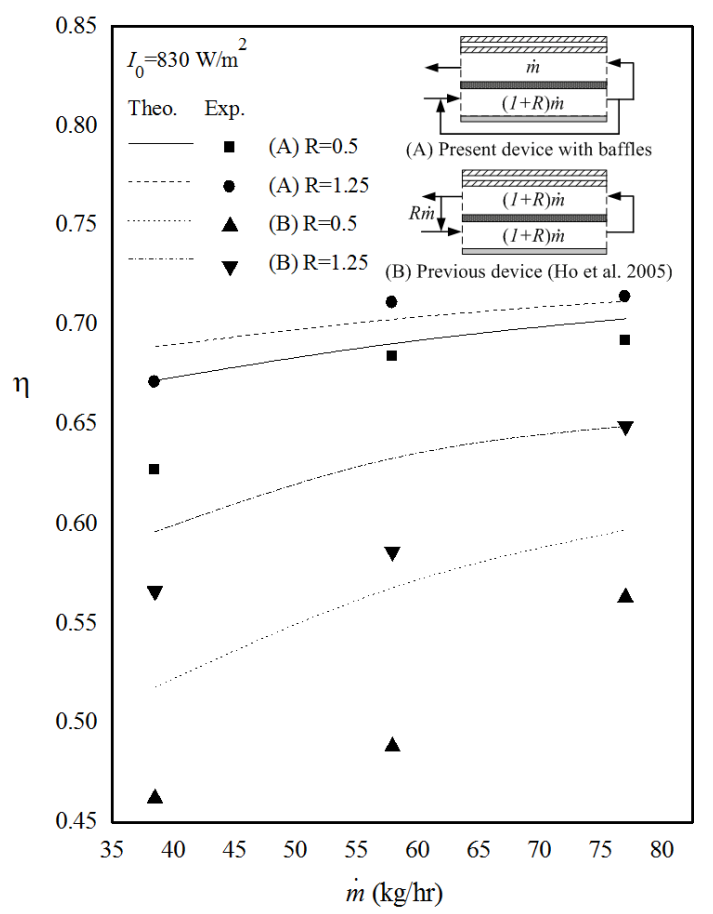

\section{Conclusions}

As demonstrated by theoretical and experimental studies, the introduction of external recycle has positive effects on the heat transfer efficiency of solar air heaters. Moreover, the advantages of baffled solar air heaters with internal fins attached provide higher turbulence and extending the heat transfer area, and thus, the enhancement of heat-transfer efficiency. It is believed that the availability of such a mathematical formulation as developed here for a recycling baffled solar air heater with internal fins attached is an important contribution to the design and analysis of double-pass devices with internal or external recycle. Although the lager mass flow rate and recycle ratio are beneficial to collector efficiency improvement, higher energy dissipation occurs at the same time when operating at a higher mass flow rate and recycle ratio. The value of $I_{D} / I_{P} v s$. recycle ratio $\mathrm{R}$ was represented with the mass flow rate as a parameter in Figure 10 to recommend an optimal design. After all, both the heat-transfer efficiency improvement and power consumption increment are significant factors to be taken into account simultaneously in designing recyclic double-pass solar air heaters.

\section{Acknowledgments}

The authors wish to thank the National Science Council of the Republic of China for its financial support.

\section{Appendix:}

Rearranging Equations $(8,9)$, one obtains, respectively:

$$
h_{r, P-c_{1}}\left[\left(T_{P}-T_{b}(z)\right)+\left(T_{b}(z)-T_{c_{1}}\right)\right]+h_{b}\left(T_{b}(z)-T_{c_{1}}\right)-U_{c_{1}-s}\left[\left(T_{b}(z)-T_{s}\right)-\left(T_{b}(z)-T_{c_{1}}\right)=0\right.
$$




$$
\begin{aligned}
& S_{0} \alpha_{p} \tau_{g}^{2}-U_{T}\left[\left(T_{P}-T_{b}(z)\right)+\left(T_{b}(z)-T_{s}\right)\right]-U_{B}\left[\left(T_{P}-T_{a}(z)\right)+\left(T_{a}(z)-T_{s}\right)\right] \\
& -h_{b}\left(T_{P}-T_{b}(z)\right)-h_{a}\left[\left(T_{P}-T_{b}(z)\right)+\left(T_{b}(z)-T_{s}\right)-\left(T_{a}(z)-T_{s}\right)\right]=0
\end{aligned}
$$

Solving Equations (A1),(A2) simultaneously for $\left(T_{p}-T_{b}(z)\right)$ and $\left(T_{b}(z)-T_{c_{1}}\right)$, we have:

$$
\begin{gathered}
T_{P}-T_{b}(z)=G_{1}\left(T_{b}(z)-T_{s}\right)+G_{2}\left(T_{b}(z)-T_{s}\right)+G_{3} \\
T_{b}(z)-T_{c_{1}}=G_{4}\left[\left(U_{c_{1}-s}+G_{1} h_{r, P-c_{1}}\right)\left(T_{b}(z)-T_{s}\right)-G_{2} h_{r, P-c_{1}}\left(T_{a}(z)-T_{s}\right)-h_{r, P-c_{1}} G_{3}\right]
\end{gathered}
$$

where:

$$
\begin{gathered}
G_{1}=\left(h_{a} \phi_{a}+U_{T}+U_{B}\right) /\left(U_{T}+U_{B}+h_{a} \phi_{a}+h_{b} \phi_{b}\right), \\
G_{2}=h_{a} \phi_{a} /\left(U_{T}+U_{B}+h_{a}+h_{b}\right), \\
G_{3}=S_{0} a_{p} \tau_{g}^{2} /\left(U_{T}+U_{B}+h_{a} \phi_{a}+h_{b} \phi_{b}\right) \\
G_{4}=\left(h_{r, p-c_{1}}+h_{b}+U_{c_{1}-s}\right)^{-1} .
\end{gathered}
$$

Again, rearranging Equations $(9,10)$, one obtains, respectively:

$$
\begin{gathered}
S_{0} \alpha_{p} \tau_{g}^{2}-U_{T}\left[\left(T_{P}-T_{a}(z)\right)+\left(T_{a}(z)-T_{s}\right)\right]-U_{B}\left[\left(T_{P}-T_{a}(z)\right)+\left(T_{a}(z)-T_{s}\right)\right] \\
-h_{b} \phi_{b}\left[\left(T_{P}-T_{a}(z)\right)+\left(T_{a}(z)-T_{s}\right)-\left(T_{b}(z)-T_{s}\right)\right]-h_{a} \phi_{a}\left(T_{P}-T_{a}(z)\right)=0 \\
h_{r, P-R}\left[\left(T_{P}-T_{a}(z)\right)+\left(T_{a}(z)-T_{R}\right)\right]+h_{1}\left(T_{a}(z)-T_{R}\right)-U_{B-S}\left[\left(T_{a}(z)-T_{s}\right)-\left(T_{a}(z)-T_{R}\right)=0\right.
\end{gathered}
$$

Solving Equations $(\mathrm{A} 9, \mathrm{~A} 10)$ simultaneously for $\left(T_{p}-T_{a}(z)\right)$ and $\left(T_{a}(z)-T_{R}\right)$, we have:

$$
\begin{gathered}
T_{P}-T_{a}(z)=G_{5}\left(T_{a}(z)-T_{s}\right)+G_{6}\left(T_{b}(z)-T_{s}\right)+G_{3} \\
T_{a}(z)-T_{R}=G_{7}\left[\left(U_{B-s}+G_{5} h_{r, P-R}\right)\left(T_{a}(z)-T_{s}\right)-G_{6} h_{r, P-R}\left(T_{b}(z)-T_{s}\right)-h_{r, P-R} G_{3}\right]
\end{gathered}
$$

where:

$$
\begin{gathered}
G_{5}=\left(h_{b} \phi_{b}+U_{T}+U_{B}\right) /\left(U_{T}+U_{B}+h_{a} \phi_{a}+h_{b} \phi_{b}\right) \\
G_{6}=h_{b 1} /\left(U_{T}+U_{B}+h_{a} \phi_{a}+h_{b} \phi_{b}\right) \\
G_{7}=\left(h_{r, P-R}+h_{a}+U_{B-s}\right)^{-1}
\end{gathered}
$$

Substitution of Equations (A3,A4) into Equation (6) and substitution of Equations (A11,A12) into Equation (7) result in Equations $(13,14)$, respectively, in which:

$$
\begin{gathered}
B_{1}=\left(-h_{r, p-c_{1}} h_{1} G_{3} G_{4}-h_{1} \phi_{1} G_{3}-U_{c_{1}-s} h_{1} G_{4}\right) / M_{b} \\
B_{2}=\left(h_{1} \phi_{1} G_{2}+h_{r, p-c_{1}} h_{1} G_{2} G_{4}\right) / M_{b} \\
B_{3}=\left(h_{1} \phi_{1} G_{3}+h_{r, p-c_{1}} h_{1} G_{3} G_{4}\right) / M_{b} \\
B_{4}=\left(h_{2} \phi_{2} G_{6}+h_{r, p-R} h_{2} G_{6} G_{7}\right) / M_{a} \\
B_{5}=\left(-h_{r, p-R} h_{2} G_{5} G_{7}-h_{2} \phi_{2} G_{5}-U_{B-s} h_{2} G_{7}\right) / M_{a} \\
B_{6}=\left(h_{2} \phi_{2} G_{3}+h_{r, p-R} h_{2} G_{3} G_{7}\right) / M_{a}
\end{gathered}
$$




$$
\begin{aligned}
& M_{b}=\left[\frac{-\dot{m} C_{P}}{W L}\right]=-\dot{m} C_{p} / A_{c} \\
& M_{a}=\left[\frac{\dot{m}(1+R) C_{P}}{W L}\right]=\dot{m}(1+R) C_{p} / A_{c} \\
& Y_{1}=\frac{\left(B_{1}+B_{5}\right)+\sqrt{\left(B_{1}-B_{5}\right)^{2}+4 B_{2} B_{4}}}{2} \\
& Y_{2}=\frac{\left(B_{1}+B_{5}\right)-\sqrt{\left(B_{1}-B_{5}\right)^{2}+4 B_{2} B_{4}}}{2} \\
& C_{1}=\frac{\left[\left(1+R-R e^{Y_{2}}\right)\left(F_{2}+F_{3}\right) / F_{1}\right] /\left(-e^{Y_{2}} \frac{I_{2}}{B_{4}}\right)-\frac{F_{2}}{F_{1}}}{\left\{1+R-R e^{Y_{1}}-\left[e^{Y_{1}} \frac{I_{1}}{B_{4}}\left(1+R-R e^{Y_{2}}\right)\right]\right\} /\left(e^{Y_{2}} \frac{I_{2}}{B_{4}}\right)} \\
& C_{2}=\frac{\left[\left(1+R-R e^{Y_{1}}\right)\left(F_{2}+F_{3}\right) / F_{1}\right] /\left(-e^{Y_{1}} \frac{I_{1}}{B_{4}}\right)-\frac{F_{2}}{F_{1}}}{\left\{1+R-R e^{Y_{2}}-\left[e^{Y_{2}} \frac{I_{2}}{B_{4}}\left(1+R-R e^{Y_{1}}\right)\right]\right\} /\left(e^{Y_{1}} \frac{I_{1}}{B_{4}}\right)} \\
& F_{1}=B_{1} B_{5}-B_{2} B_{4} \\
& F_{2}=B_{3} B_{4}-B_{1} B_{6} \\
& F_{3}=B_{3} B_{5}-B_{2} B_{6} \\
& I_{1}=Y_{1}-B_{4}-B_{5} \\
& I_{2}=Y_{2}-B_{4}-B_{5}
\end{aligned}
$$

\section{References}

1. Close, D.J.; Dunkle, R.V. Behaviour of adsorbent energy storage beds. Sol. Energy 1976, 18, 287-292.

2. Liu, C.H.; Sparrow, E.M. Convective-radiative interaction a parallel plate channel-application to air-operated solar collectors. Int. J. Heat Mass Transf. 1980, 23, 1137-1146.

3. Seluck, M.K. Solar Air Heaters and Their Applications; Sayigh, A.A.M., Ed.; Academic Press: New York, NY, USA, 1977.

4. Tan, H.M.; Charters, W.W.S. Experimental investigation of forced-convective heat transfer for fully-developed turbulent flow in a rectangular duct with asymmetric heating. Sol. Energy 1970, 13, 121-125.

5. Whillier, A. Plastic covers for solar collectors. Sol. Energy 1963, 7, 148-154.

6. Yeh, H.M.; Ho, C.D.; Hou, J.Z. Collector efficiency of double-flow solar air heaters with fins attached. Energy 2002, 27, 715-727. 
7. Kreith, F.; Kreider, J.F. Principles of Solar Engineering, 2nd ed.; McGraw-Hill: New York, NY, USA, 1978.

8. Duffie, J.A.; Beckman, W.A. Solar Engineering of Thermal Processes, 3rd ed.; Wiley: New York, NY, USA, 1980.

9. Tonui, J.K.; Tripanagnostopoulos, Y. Improved PV/T solar collectors with heat extraction by forced or natural air circulation. Renew. Energy 2007, 32, 623-637.

10. Gao, W.; Lin, W.; Liu, T.; Xia, C. Analytical and experimental studies on the thermal performance of cross-corrugated and flat-plate solar air heaters. Appl. Energy 2007, 84, 425-441.

11. Mohamad, A.A. High efficiency solar air heater. Sol. Energy 1997, 60, 71-76.

12. Verma, S.K.; Prasad, B.N. Investigation for the optimal thermohydraulic performance of artificially roughened solar air heaters. Renew. Energy 2000, 20, 19-36.

13. Yeh, H.M. Theory of baffled solar air heaters. Energy 1992, 17, 697-702.

14. Garg, H.P.; Sharma, V.K.; Bhargava, A.K. Theory of multiple-pass solar air heaters. Energy 1985, 10, 589-599.

15. Ho, C.D.; Yang, W.Y. An analytical study of heat-transfer efficiency in laminar counterflow concentric circular tubes with external refluxes. Chem. Eng. Sci. 2003, 58, 1235-1250.

16. Ho, C.D.; Yeh, C.W.; Hsieh, S.M. Improvement in device performance of multi-pass flat-plate solar air heaters with external recycle. Renew. Energy 2005, 30, 1601-1621.

17. Ho, C.D.; Yeh, H.M.; Chiang, S.C. Mass-Transfer enhancement in double-pass mass exchangers with external refluxes. Ind. Eng. Chem. Res. 2001, 40, 5839-5846.

18. Ho, C.D.; Yeh, H.M.; Wang, R.C. Heat-transfer enhancement in double-pass flat-plate solar air heaters with recycle. Energy 2005, 30, 2796-2817.

19. Bannett, C.O.; Myers, J.E. Momentum, Heat, and Mass Transfer, 3rd ed.; McGraw-Hill: New York, NY, USA, 1982.

20. Chou, W.H. A Study in Collector Efficiency of Baffled Solar Air Heaters. M.S. Thesis, Cheng Kung University: Tainan, Taiwan, 1987.

21. Yeh, H.M. Energy balances for upward-type baffled solar air heaters. Energy 1994, 19, 919-924.

22. Klein, S.A. Calculation of monthly average transmittance-absorptance product. Sol. Energy 1979, 23, 547-551.

23. Hottel, H.C.; Woertz, B.B. Performance of flat-plate solar-heat collectors. Trans. ASME 1942, 64, 91-104.

24. Kays, W.M. Convective Heat and Mass Transfer, 2nd ed.; McGraw-Hill: New York, NY, USA, 1980.

25. McAdams, W.H. Heat Transmission, 3rd ed.; McGraw-Hill: New York, NY, USA, 1954.

26. Heaton, H.S.; Reynolds, W.C.; Kays, W.M. Heat transfer in annular passages. Simultaneous development of velocity and temperature fields in laminar flow. Int. J. Heat Mass Transf. 1964, 7, 763-781.

(C) 2013 by the authors; licensee MDPI, Basel, Switzerland. This article is an open access article distributed under the terms and conditions of the Creative Commons Attribution license (http://creativecommons.org/licenses/by/3.0/). 